\title{
Comentarios relevantes sobre el índice de confiabilidad en los funcionarios judiciales del Estado de Tabasco
}

\author{
Guillermo Ramírez Armas* \\ Carlos Martínez** \\ Recibido: 10 marzo \\ Dictaminado: 3 de abril
}

\section{Resumen}

En el presente artículo permite conocer al lector, el índice de confiabilidad que presentan de los servidores públicos que se encuentran al frente de los órganos judiciales, ya que los ciudadanos del estado de Tabasco expresan una gran decepción y molestia por la poca eficacia de los encargados del poder judicial, traduciéndose como un alejamiento de las personas ante estas instituciones por la poca confiabilidad que generan.

Cuando los estándares de confiabilidad no son los efectivos y eficaces dentro del servicio judicial, se recae en una supuesta corrupción, y por lo mismo hay varios factores que contribuyen a que surja ésta. Las causas institucionales de la corrupción no son siempre las mismas, pues con el paso del tiempo y con un nuevo liderazgo, algunas de las medidas anticorrupción pueden distorsionarse y convertirse en un punto de origen para otras formas de corrupción (Klitgaard, MacLean-Abaroa, Parris 2000). Por lo mismo, los resultados que se obtengan de este estudio pueden explicar una faceta de la corrupción, sin embargo, no son suficientes para explicar las demás manifestaciones de la corrupción.

Palabras clave: Corrupción, Poder Judicial, Política, Instituciones, Marco jurídico, Trafico de Influencias, Nepotismo, Soborno, Anticorrupción

\footnotetext{
* Docente Investigador Universidad Juárez Autónoma de Tabasco grarmas41@gmail.com

** Estudiante Universidad Juárez Autónoma de Tabasco car_ma1697@hotmail.com
} 


\title{
Relevant comments on the reliability index in the judicial officials of the State of Tabasco
}

\begin{abstract}
In this article allows the reader to know the reliability index that they present of the public servants who are in front of the judicial organs, since the citizens of the state of Tabasco express great disappointment and annoyance for the inefficiency of the managers of the judicial power, translating as a remoteness of the people before these institutions for the unreliability they generate.

When the standards of reliability are not effective and effective within the judicial service, there is a supposed corruption, and therefore there are several factors that contribute to its emergence. The institutional causes of corruption are not always the same, for with the passage of time and with new leadership, some anti-corruption measures can be distorted and become a point of origin for other forms of corruption (Klitgaard, MacLean-Abaroa, Parris 2000). Therefore, the results obtained from this study may explain one facet of corruption, however, are not sufficient to explain the other manifestations of corruption.

Key words: Corrupción, Poder Judicial, Política, Instituciones, Marco jurídico, Trafico de Influencias, Nepotismo, Soborno, Anticorrupción
\end{abstract}

\section{Sumario}

I.Introduccion II. Primeros antecedentes de la corrupción; 2.1 Antecedentes en México; III. Definición de Corrupción; 3.1 El Soborno; 3.2 Nepotismo; 3.3 Malversación de fondos y desfalco; 3.4 Extorsión; IV. Convenciones internacionales; 4.1. Ley Federal Anticorrupción en Contrataciones Públicas; 4.2. El nuevo sistema de combate a la corrupción en México; V. La corrupción en México; 5.1 Sistema de justicia y la corrupción; 5.2. Costos de la corrupción; 5.3. Causas de la corrupción; 5.4. Carta Tabasco y la lucha con la corrupción; VI. Conclusión; Bibliografía.

\section{Introducción}

El objetivo del tema dar a conocer los aspectos relevantes sobre el índice de confiablidad de los funcionarios judiciales en México. Los ciudadanos tabasqueños muestran un reproche a la eficiencia de las instituciones judiciales 
ya que los procesos para la impartición de justicia son entorpecidos por medios corruptivos donde muchas veces el tráfico de influencias o cualquier modo de corrupción son quienes dan fallo hacia el delincuente.

Para México y Tabasco no es extraño hablar sobre la corrupción. Desde hace tiempo este tema ha sido común, aunque tal vez antes no se comentaba tanto en los medios. Hoy en día toma un gran auge ya que cada vez más se presenta esta problemática una de las instituciones que presenta este problema es el poder judicial, desde el secretario que pide cuota para poder hablar con el juez, como el abogado que soborna al juez para agilizar los trámites del sentenciado y salir libre.

\section{Primeros antecedentes de la corrupción}

Los sobornos, el tráfico de influencias... no nacieron ayer. Recientemente se ha descubierto el primer caso conocido de corrupción. Se remonta al antiguo Egipto y se lo conoce como el Tebasgate. El investigador egipcio Ahmad Saleh descifró la inscripción de un papiro en el que se cuenta la historia de un funcionario de Tebas llamado Peser que, en tiempos del faraón Ramsés IX, dirigía una trama en connivencia con una banda de saqueadores de tumbas. Según explica Saleh, el caso se cerró con un proceso en el que ni Peser ni otros cargos públicos implicados fueron condenados. ${ }^{1}$

Contra el cobro de falsos impuestos existen, además, otros documentos que demuestran que la corrupción estaba arraigada en las sociedades antiguas. Sin salir de Egipto, tenemos el Decreto de Horemheb, de 1300 a. C., y en el que ya se recogen normas contra estas prácticas. "Se castigará con implacable rigor a los funcionarios que, abusando de su poder, roben cosechas o ganado a los campesinos bajo el pretexto de cobrar impuestos. El castigo será de cien bastonazos. Si el involucrado fuera un juez, la pena será de muerte", se señala en dicho código.

1 Ades, Alberto y Di Tella, Rafael. (1997), "National History Champions and Corruption: Some Unpleasant Interventionist Arithmetic”, Economic Journal, vol. 107, pp. 1023-1042. 
Sobra decir que dicho reglamento no extirpó el virus de la corrupción, que encontramos siglos después igual de arraigado en la Grecia clásica. Hasta las más ilustres figuras de la civilización helena se vieron salpicadas por escándalos de esta índole.

Como Fidias, el arquitecto que construyó el Partenón, a quien sus contemporáneos echaron en cara quedarse con parte de los fondos destinados a las obras. Y el gran orador Demóstenes, acusado de delitos tan variopintos como chantajear a jóvenes adinerados con los que mantenía relaciones o quedarse con el dinero depositado en un tribunal como prueba de un delito. ${ }^{2}$

\subsection{Antecedentes en México}

Se ha dicho que sus raíces están en la época colonial. El poder patrimonial absoluto de los monarcas españoles sobre sus dominios, transferido caso intacto a sus representantes en las Indias, los virreyes, habría convertido el ejercicio de los puestos públicos en un negocio privado, hábito que a su vez habría persistido a través de los siglos. Es verdad que el enriquecimiento de los oficiales con sus puestos no estaba mal visto por la Corona que incluso propiciaba la "venta de oficios". Es verdad también que sólo ahora comienza a desvanecerse la idea de que los políticos son los dueños del país. Pero la vida política colonial era menos opresiva de lo que se cree y su herencia menos decisiva de lo que parece. Piénsese, por ejemplo, en la maravillosa institución del Juicio de Residencia. Cuando los virreyes cesaban en sus funciones o eran transferidos a otros reinos, sufrían un arraigo forzoso para enfrentar, y en su caso reparar, los agravios que hubiesen inflingido a particulares o corporaciones. Si el virrey moría en funciones, el resarcimiento recaía sobre su sucesión. En este sentido, la Colonia era más democrática que la época actual: ningún ex presidente ha tenido que responder, no se diga resarcir a la nación, por sus faltas, robos o asesinatos.

Los criollos -escribía Alamán- eran "prontos para emprender y poco prevenidos en los medios a ejecutar, entregándose con ardor a lo presente y atendiendo poco a lo venidero...". Iturbide hizo negocios turbios en sus años de general invicto, Santa Anna tuvo haciendas en México y Colombia, pero ambos

2 Banfield, Edward. (1975), "Corruption as a feature of mexican history", Journal of Law and Economics, vol. 18, núm. 3, pp. 587-605. 
fueron despilfarrados, desidiosos, descuidados. Buscaban menos el poder que el amor de sus compatriotas. Soñaban con guirnaldas de oliva y un sepulcro de honor. El dinero no estaba en su horizonte práctico ni axiológico. Además, de haber querido enriquecerse, el pobre erario se los hubiese impedido.

Los liberales de la Reforma tuvieron todas las cualidades cívicas incluidas, por supuesto, la honradez. (Juárez pedía préstamos personales para sobrevivir). Pero como sabían que los hombres son falibles, crearon una Constitución que limitaba las fallas de un posible Ejecutivo dispendioso o corrupto, por tres vías: la Comisión de Hacienda de la Cámara de Diputados, la Suprema Corte de Justicia y una prensa libérrima. Estas instituciones llamaron a cuentas al ex presidente Manuel González en 1885. México había vivido su primer momento de apertura económica caracterizado sobre todo por la febril construcción de los ferrocarriles. Al amparo del gobierno se hicieron negocios ilícitos que se tradujeron en un déficit fiscal escandaloso para esos tiempos y que estuvo a punto de provocar la consignación del secretario de Hacienda y el tesorero de la Federación. Don Porfirio, pérfido instigador de la maniobra, terminó por absolver a su compadre y de ese modo se enfiló, sin rival alguno, hacia la reelección perpetua, pero el precedente se había sentado. El Presidente, dueño de un dominio político absoluto, podía otorgar mercedes, prebendas, concesiones con la liberalidad de un rey, pero en lo personal tenía que ser, y parecer, honrado. Para que la Cámara, la Corte y la prensa no tuvieran que llamar a cuentas, las cuentas quedarían a cargo del ministro de Hacienda, quien ejercería un manejo financiero responsable y auto contenido en el cual cabían ciertos favores y preferencias, pero no la corrupción. Por lo demás, cosa que con frecuencia se olvida, en tiempos porfirianos los niveles medios del aparato judicial funcionaban con eficacia y honestidad.

\section{Definición de Corrupción}

La corrupción es un problema multifacético y complejo con distintas causas y efectos. La corrupción va desde el caso aislado que involucra a un solo burócrata, hasta convertirse en un fenómeno general que origina una serie de distorsiones 
en la economía. La definición que utilizaremos será la del Banco Mundial: La corrupción es el abuso de poder público en beneficio propio. Esta definición nos indica que quién comete un acto corrupto está en una posición de poder y que está recibiendo algún tipo de beneficio (ya sea monetario o no) que no sea procedente o que simplemente es ilegal. Lo que necesitamos añadir a esta definición es que la corrupción no sólo ocurre en el sector público sino también en el privado. Ahora bien, vamos a señalar algunos de los tipos más importantes de corrupción.

\subsection{El Soborno ${ }^{3}$}

Este tipo de corrupción implica el uso inapropiado del servicio público (y también del privado) para obtener beneficios materiales. Este es parecido a la extorsión sin embargo, en el soborno hay un acuerdo mutuo, entre sobornado y sobornador, mientras que en la extorsión hay una imposición por parte del que recibe el pago, en realidad hay muchos casos en que la línea entre los dos tipos de corrupción es muy tenue ${ }^{4}$. Dentro del soborno hay dos clasificaciones. El primero, es el pago que se hace por recibir un servicio con diligencia (speed payment) y el segundo es cuando se hace un pago que busca cambiar una decisión, violando leyes, reglas y reglamentos (distortive payment).

3 Este tipo de corrupción está contemplado en México dentro del Código Penal Federal como Cohecho en el artículo 222, fracciones I y II. La fracción I dice que [cometen el delito de cohecho] El servidor público que por sí, o por interpósita persona solicite o reciba indebidamente para sí o para otro, dinero o cualquiera otradádiva, o acepte una promesa, para hacer o dejar de hacer algo justo o injusto relacionado con susfunciones. La fracción II dice que [cometen el delito de cohecho] El que de manera espontánea dé u ofrezcadinero o cualquier otra dádiva a alguna de las personas que se mencionan en la fracción anterior, para quecualquier servidor público haga u omita un acto justo o injusto relacionado con sus funciones. Cabe notar que el sobornado puede incurrir en otros delitos contemplados en el Código Penal Federal.

4 Dentro del estudio de Transparencia Mexicana se registra el acto corrupto cuando se paga una mordida por obtener el servicio, no se hace la distinción entre extorsión o soborno. 


\subsection{Nepotismo 5}

Este tipo de corrupción no involucra directamente un pago monetario. Una persona aprovecha su posición dentro de un organismo para emplear a un amigo, familiar o conocido que no tiene los méritos para el puesto o que simplemente no pasó por un proceso de selección regular; también podría estar relacionado con favores ilegales otorgados a parientes y amigos. Este tipo de corrupción tal vez sea el más difícil de identificar porque no existe una transacción monetaria. También es cierto que en muchos países el nepotismo no es visto como un acto de corrupción, sino como algo necesario, un mecanismo de ayuda que está contemplado en la sociedad. En México podemos identificar un caso de nepotismo singular, el de los aviadores, trabajadores que están en la nómina pero no se presentan a trabajar. Este caso es más grave, pues en los otros casos de nepotismo el trabajador sí labora, mientras que en este último caso hay únicamente una transferencia monetaria por parte del gobierno al aviador.

\subsection{Malversación de fondos y desfalco ${ }^{6}$}

Este difiere de los demás tipos de corrupción en que el actor corrupto, mediante mecanismos fraudulentos, extrae recursos de un organismo público o privado. Aquí entra el fraude y el robo al presupuesto. No existe el personaje del

\footnotetext{
5 El nepotismo es el delito del ejercicio indebido de servicio público contemplado en el artículo 214, fracción I del Código Penal Federal. El artículo 214, fracción I dice que [comete el delito de ejercicio indebido deservicio público, el servidor público que] ejerza las funciones de un empleo, cargo o comisión, sin habertomado posesión legítima, o sin satisfacer todos los requisitos legales. Para el caso de los trabajadores fantasmas (aviadores) está el delito de abuso de autoridad contemplado en el artículo 215, fracción X en el Código Penal Federal. El artículo 215, fracción X dice que [cometen el delito de abuso de autoridad losservidores públicos que incurran en alguna de las conductas siguientes] cuando en el ejercicio de susfunciones o con motivo de ellas, otorgue empleo, cargo o comisión públicos, o contratos de prestación deservicios profesionales o mercantiles o de cualquier otra naturaleza, que sean remunerados, a sabiendas de que no se prestará el servicio para el que se les nombró, o no se cumplirá el contrato otorgado.

6 Éstos son contemplados como los delitos de abuso de autoridad en el artículo 215, fracción VIII, y peculadoen el artículo 223, fracción I, ambas dentro del Código Penal Federal. El artículo 215, fracción VIII dice que [cometen el delito de abuso de autoridad los servidores públicos que incurran en alguna de las conductas siguientes] cuando haga que se le entreguen fondos, valores u otra cosa que no se le haya confiado a él y se los apropie o disponga de ellos indebidamente. El artículo 223, fracción I dice que [comete el delito depeculado] todo servidor público que para usos propios o ajenos distraiga de su objeto dinero, valores, fincas o cualquier otra cosa perteneciente al Estado, al organismo descentralizado o a un particular, si por razón de su cargo los hubiere recibido en administración, en depósito o por otra causa.
} 
sobornador. También supone un sistema más elaborado y más complejo, que por lo mismo va a ser difícil de detectar.

\subsection{Extorsión ${ }^{7}$}

Cómo ya se mencionó antes, este es muy parecido al soborno, solo que aquí el pago es demandado por el burócrata. Morris (1991) encuentra que este tipo de corrupción junto con el fraude es el más frecuente en México. La extorsión implica que el cliente es obligado a pagar un soborno. Esto indica que el extorsionador tiene una ventaja, poder de negociación. Este poder puede ser la discrecionalidad que tiene el burócrata para otorgar el servicio.

MarcoJurídico.

\section{Convenciones internacionales}

México ha participado, firmado y ratificado tres convenciones internacionales de combate contra la corrupción dentro y fuera de sus fronteras: la Convención Interamericana contra la Corrupción (OEA 1997), la Convención para Combatir el Cohecho de Servidores Públicos en Transacciones Comerciales Internacionales (OCDE 1999) y la Convención de las Naciones Unidas contra la Corrupción (ONU 2004). Éstas tienen como principal objetivo definir e identificar actos de corrupción e impulsar a los países participantes a adecuar su legislación interna a los estándares internacionales. Además, pretenden impulsar la cooperación entre países en casos de corrupción internacional con el fin de terminar con las trabas legales que entorpecen Investigaciones internacionales. ${ }^{8}$

Los compromisos más importantes aceptados por México dentro de las

7 La extorsión está contemplada en el artículo 390 y en el 218 como concusión, ambos artículos dentro del Código Penal Federal. El artículo 390 señala que comete el delito de extorsión al que sin derecho obligue aotro a dar, hacer, dejar de hacer o tolerar algo, obteniendo un lucro para sí o para otro o causando aalguien un perjuicio patrimonial. El artículo 218 dice que comete el delito de concusión el servidor públicoque con el carácter de tal y a título de impuesto o contribución, recargo, renta, rédito, salario o emolumento, exija, por sí o por medio de otro, dinero, valores, servicios o cualquiera otra cosa que sepa no ser debida, o en mayor cantidad que la señalada por la Ley.

8 Maria Amparo Casar. (2010). Anatomia de la corrupcion. Mexico, DF.: CIDE. 
tres convenciones son la instauración de medidas preventivas de combate a la corrupción mediante mecanismos de capacitación, control interno y participación de la sociedad civil; la aplicación de códigos de ética para funcionarios públicos y; la tipificación de actos de corrupción de servidores públicos como delitos así como medidas de prevención y sanción del soborno internacional. Si bien dichas convenciones sirven a México como guía y al mismo tiempo como una presión para mejorar el combate contra la corrupción, el respeto a la "soberanía" de los países participantes ha provocado que los compromisos adquiridos sean laxos y ambiguos. Por regla general, los mandatos de las convenciones permiten al país signatario aplicar la resolución de conformidad con sus leyes y procedimientos por lo que la efectividad de las resoluciones queda normalmente mermada.

En consecuencia, la participación en convenciones internacionales no asegura un mejor desempeño nacional.

\subsection{Ley Federal Anticorrupción en Contrataciones Públicas}

Capítulo Primero Disposiciones Generales

Artículo 1. La presente Ley es de orden público y de interés general y tiene por objeto:

I. Establecer las responsabilidades y sanciones que deban imponerse a las personas físicas y morales, de nacionalidad mexicana y extranjeras, por las infracciones en que incurran con motivo de su participación en las contrataciones públicas de carácter federal previstas en esta Ley, así como aquéllas que deban imponerse a las personas físicas y morales de nacionalidad mexicana, por las infracciones en que incurran en las transacciones comerciales internacionales previstas en esta Ley, y

II. Regular el procedimiento para determinar las responsabilidades y aplicar sanciones, y

III. Establecer las autoridades federales competentes para interpretar y aplicar esta Ley.

Artículo 2. Son sujetos de la presente Ley:

I. Las personas físicas o morales, de nacionalidad mexicana o extranjeras, que participen en las contrataciones públicas de carácter federal, en su calidad de interesados, licitantes, 
invitados, proveedores, adjudicados, contratistas, permisionarios, concesionarios o análogos;

II. Las personas físicas o morales, de nacionalidad mexicana o extranjeras, que en su calidad de accionistas, socios, asociados, representantes, mandantes o mandatarios, apoderados, comisionistas, agentes, gestores, asesores, consultores, subcontratistas, empleados o que con cualquier otro carácter intervengan en las contrataciones públicas materia de la presente Ley a nombre, por cuenta o en interés de las personas a que se refiere la fracción anterior. ${ }^{9}$

La presente ley se encarga se castigar a las personas que cometan corrupción en las contrataciones públicas es decir que toda persona que beneficie a una cierta empresa por sobre otras para realizar obras de carácter federal serán castigadas conforme a esta ley.

Hablo solo de esta ley en el ámbito de contrataciones publica porque en México no hay otras leyes que regulan la corrupción en un aspecto general más adelante hablare sobre el nuevo sistema anticorrupción que los diputados están proponiendo.

\subsection{El nuevo sistema de combate a la corrupción en México}

El pasado 26 de febrero, la Cámara de Diputados aprobó una reforma o modificación a los artículos 22, 28, 41, 73, 74, 76, 79, 104, 109, 113, 114, 116 y 122 de la Constitución Política de los Estados Unidos Mexicanos, y la denominación del Título Cuarto de la ley fundamental a "De las Responsabilidades de los Servidores Públicos, Particulares Vinculados con faltas administrativas graves o hechos de Corrupción, y Patrimonial del Estado".

Se alude a un "sistema nacional anticorrupción" que contará con un Comité Coordinador integrado por los titulares de la Auditoría Superior de la Federación, de la fiscalía responsable del combate a la corrupción, de la Secretaría del Ejecutivo Federal responsable del control interno, por el magistrado presidente del Tribunal Federal de Justicia Administrativa, el comisionado presidente del organismo garante que establece el artículo $6^{\circ}$. de la Constitución, así como por un representante del Consejo de la Judicatura Federal y otro del Comité de Participación Ciudadana.

9 Ley anticorrupción en contrataciones publicas 
La reforma, según el Dictamen, obedece a los siguientes aspectos: fiscalización, investigación, control, vigilancia, sanción, transparencia, rendición de cuentas y participación ciudadana.

Ahora es necesario mencionar otros problemas, como el de la deficiente construcción típica del ilícito de enriquecimiento ilícito y sus requisitos de procedencia, que lo transforman en un delito imposible. Lo que impacta en la reforma al artículo 22 constitucional y su pretensión de aplicar la extinción de dominio en esos casos.

El involucramiento de las Cámaras de Diputados y Senadores en la designación de algunos titulares de órganos de control interno, que se destaca en los artículos 28, 41, 74 y 76, lo que lleva a la politización, partidización y al compadrazgo o nepotismo en la asignación de puestos en los órganos de control interno en los organismos con autonomía constitucional.

La centralización del combate a la corrupción y de las responsabilidades administrativas, vía leyes generales, plasmada en el artículo 73 constitucional, lo que en sí mismo no es negativo, pero que impacta en nuestro federalismo que se resiste a consolidarse y merma la competencia de las entidades federativas los estados- en materia de combate a la corrupción y la consolidación de una administración pública apegada a la ley en el ámbito local. También el llevar algunos contenidos orgánicos del Tribunal Federal de Justicia Administrativa - que se crea- a la Constitución, lo que demuestra un desconocimiento de la técnica legislativa y una desnaturalización de la Constitución al transformarla en "ley reglamentaria" de ese tribunal.

Un punto positivo es la declaración de situación patrimonial y de intereses del artículo 108 constitucional, sin embargo, ¿no era en sí misma la declaración de situación patrimonial bien entendida una declaración de intereses? Además, lamentablemente no se aprovechó la oportunidad para romper el círculo de impunidad con el que se protege al presidente de la República contenido en ese mismo precepto. ${ }^{10}$

Asimismo, destaca en el artículo 109 la responsabilidad de la Auditoría,

10 Daniel Márquez Gomez. (2015). El nuevo sistema de combate a la corrupción en México. 27 de mayo de 2015, de Universidad Nacional Autónoma de México Sitio web: http://biblio.juridicas.unam.mx/revista/ HechosyDerechos/cont/27/art8.htm 
las contralorías y el Consejo de la Judicatura de "investigar y sustanciar" faltas graves, lo que sobrecarga a esos órganos que ya tienen encomendadas labores administrativas cotidianas.

Por lo anterior, la reforma aprobada en materia de combate a la corrupción está mal diseñada, mal pensada, no toma como punto de partida la experiencia del pasado, así como tampoco construye un sistema confiable de combate a la corrupción para el presente, por lo que de nuevo, en algunos años esperemos que no sean treinta y tres, tendremos que repensar el combate a la corrupción en nuestro país.

\section{La corrupción en México}

El problema de la corrupción en el México moderno es un tema antiguo, su génesis es parte de dos ideas básicas: una administración pública que se considera patrimonio personal del poderoso en turno (recuérdese el tema de la venta de cargos públicos en el siglo XVI, en la época de Felipe II, en España) y la anomía legal que se deriva de una administración pública acostumbrada a violar la ley (el famoso acátese, pero no se cumpla). En el siglo XX la renovación moral de 1982 nos heredó la reforma del Título IV de la Constitución Política de los Estados Unidos Mexicanos, con la pretensión de contar con herramientas sólidas para combatir la corrupción; sin embargo, el experimento terminó en fracaso: treinta y tres años después la corrupción continúa siendo uno de los problemas estructurales del Estado mexicano.

La corrupción en México, durante los años del PRI, según el modelo de Morris (1991), se explica dentro del estado corporativo, por una dinámica cíclica que se desarrolla tomando cómo periodo el sexenio del presidente.

El ciclo comienza con el primer año, en el que el nuevo gobierno se dedica a cubrir los puestos burocráticos y diseñar los nuevos programas y políticas. Hasta los años intermedios el presidente y sus altos funcionarios realizan y promueven vastos programas y reformas gubernamentales. En los dos últimos años de gobierno ya no se inician nuevos programas, pero se destina mayores recursos 
a los ya establecidos; los funcionarios públicos empiezan a preocuparse por su futuro, por lo tanto se dedican a mejorar sus perspectivas políticas y económicas, dadas la posibilidad de no tener empleo para el siguiente sexenio. Los incentivos del último año han cambiado: la ausencia de seguridad en el empleo y de un sólido fondo para el retiro, aunado a una mayor tolerancia a la corrupción, llevan a los burócratas a capitalizarse mediante actos de corrupción, cómo puede ser el soborno o la malversación de fondos públicos. El incremento en el gasto gubernamental y la débil campaña anticorrupción crean un ambiente propicio para la corrupción. Al comenzar el nuevo sexenio se condena públicamente la corrupción y por tener una planta nueva de personal, los burócratas están en un proceso de aprendizaje. Además, todavía no existe la presión del final del sexenio por enriquecerse mediante prácticas corruptas. Hay un mayor control de la corrupción pues en el discurso político se está condenando a la del sexenio anterior. $^{11}$

Morris dice que existen dos patrones dentro del sexenio, uno el de la corrupción y otro el de la campaña anticorrupción. Los dos van en sentidos contrarios, son un espejo del otro. A principio del sexenio la campaña anticorrupción está en su punto más álgido, mientras que la corrupción está llegando a un punto bajo, conforme avanza el sexenio la corrupción va en aumento culminando en el último año, mientras que la campaña anticorrupción va en descenso.

\subsection{Sistema de justicia y la corrupción}

El sistema de justicia en México se encuentra estancado. La corrupción de ministros, magistrados, jueces y abogados y la ineficacia de empleados del Ministerio Público han provocado que la población ya no tenga confianza en las instituciones y en los encargados de procurar e impartir justicia en el país.

Según organismos internacionales de derechos humanos, así como la Organización de las Naciones Unidas (ONU), México es uno de los pocos países en Latinoamérica que siguen arrastrando un sistema inquisitorio que deja vulnerable a las víctimas ante los abusos del poder.

La ONU indica que en el país la impunidad es de entre el 95 y 98 por ciento,

11 Morris, Stephen. (1991), Corruption and Politics in Contemporary Mexico, Tuscaloosa, University of Alabama Press. 
derivado de que entre el 50 y el 70 por ciento de los jueces son corruptos. La población ya no tiene confianza en las autoridades y esto se refleja en que sólo uno de cada cuatro crímenes es reportado y sólo uno de cada 10 delitos termina en arresto. Además - dice un informe de la ONU- las víctimas son tratadas por el Ministerio Público como si fueran delincuentes. ${ }^{12}$

Los problemas en el sistema de justicia mexicano según especialistas en derecho penal-, provienen desde su origen. Al contar con un sistema inquisitorio y no acusatorio como en los países más avanzados en materia penal, en donde el Estado tiene la carga de la prueba, en México no se cuenta con igualdad de condiciones entre las partes en los procesos penales. Además, los procedimientos administrativos se han vuelto obsoletos y las personas que trabajan en esas instituciones son ineficientes y corruptas.

\subsection{Costos de la corrupción}

Según los datos obtenidos en la encuesta de corrupción y buen gobierno, realizada en el 2001, Transparencia Mexicana calcula que en México se pagan 214 millones de mordidas en un año, la mordida promedio es de 109.50 pesos, esto arroja un gasto total de 23,433 millones de pesos por concepto de mordidas 12. Además, se calculó que la industria del narcotráfico hace un pago anual de 208 millones de dólares 13 por concepto de corrupción (Loret de Mola, 2000).

Pongamos un ejemplo: en la construcción de un edificio se están utilizando materiales de baja calidad que no cumplen con los estándares legales, sin embargo se soborna al inspector para que reporte que se usaron los materiales adecuados; el resultado es que el edificio va a ser más inseguro, éste costo no lo enfrenta el inspector ni los constructores, pues ellos no van a usarlo, el costo lo van a enfrentar las personas que utilicen el edificio, el costo lo enfrenta un tercero. En Economía, cuando un actor económico afecta directamente el bienestar de otro, sin ser reflejado en cambios en los precios de mercado, se dice que este efecto es una externalidad. En el caso anterior, los que renten o compren el edificio no van a pagar menos porque tenga una menor calidad, ellos adquieren el edificio con la idea que cumple con los Requerimientos mínimos de calidad. La

12 Morris, Stephen. (1991), Corruption and Politics in Contemporary Mexico, Tuscaloosa, University of Alabama Press. 
transacción corrupta - el soborno - causa una externalidad negativa pues afecta directamente a los que van a usar el edificio, sin haber sido alterado el precio del edificio, debido a la menor calidad. El costo que van a enfrentar los que utilicen el edificio va a estar determinado por la calidad de los materiales utilizados, y no por cuánto fue el soborno pagado. El monto del soborno va a estar determinado por otros factores, cómo el proceso del soborno y la información que tienen el inspector y los constructores. ${ }^{13}$

\subsection{Causas de la corrupción}

Un modelo conceptual útil para analizar la corrupción — sobretodo el sobornoes el modelo de agente y principal. El agente es una persona que ha aceptado la obligación de actuar a nombre de su principal en ciertas actividades (posiblemente mediante un contrato laboral); por lo que tiene que seguir los intereses del principal como si fueron los suyos. El principal es una persona u organización. Este enfoque define a la corrupción en términos de la divergencia entre los intereses del principal17 y los del agente: la corrupción ocurre cuando el agente traiciona al principal (y los intereses de éste) por buscar su propia conveniencia. Este enfoque enfatiza que la corrupción es cuestión de grados, el principal quiere inducir el nivel óptimo de corrupción, que probablemente no es igual a cero.

Si suponemos que el principal entiende que el agente está tentado a volverse corrupto, la tarea del primero es inducir que el agente cumpla sus obligaciones hasta el nivel óptimo - inducir el nivel óptimo de esfuerzo de servicio público y el nivel óptimo de comportamiento corrupto. En el caso del soborno, el principal también está interesado en inducir la conducta apropiada por el cliente (el sobornador en potencia). El agente va a cometer un acto corrupto si los beneficios esperados de hacerlo superan los costos esperados. Klitgaard (1988) identifica tres factores fundamentales que contribuyen a la decisión del agente a volverse corrupto. El primero es el monopolio de poder; si el agente está encargado de ofrecer un servicio al público y es el único que lo provee, sus posibles ganancias si pide un soborno son mayores. El segundo factor es la discrecionalidad;

13 Loret de Mola, Carlos. (2000), Impacto económico del narcotráfico en México: Estimaciónde las utilidades de los cárteles y su influencia sobre el nivel de vida de las familias productoras de droga en Badiraguato, Sinaloa, Tesis de Licenciatura, ITAM. 
si el agente puede decidir a quién puede otorgarle al servicio y a quién no, puede extorsionar a los clientes. Por último está la rendición de cuentas, que básicamente consiste en que tanto tiene que responder el agente por sus actos; si constantemente están supervisando el desempeño del agente, éste tiene menos incentivos a volverse corrupto. Los primeros dos factores tienen una relación positiva con la corrupción (si alguno de los dos aumenta, también aumenta la corrupción), mientras que la rendición de cuentas va en sentido contrario a la corrupción (mayor rendición de cuentas implica un menor nivel de corrupción). El monopolio del burócrata va a estar determinado, principalmente, por cuestiones estructurales. La discrecionalidad de los burócratas está constreñida por la habilidad del principal de crear reglas claras y de supervisar a los agentes. La rendición de cuentas va a depender de varias cosas, entre ellas la transparencia y la calidad de las instituciones democráticas.

En el clásico análisis de Becker (1968), éste decía que dos de los principales factores que determinaban la oferta de actos criminales - en este caso actos corruptos - son primero, la probabilidad de ser sancionado y segundo, el monto de la sanción. La corrupción depende negativamente de la probabilidad de ser sancionado y negativamente de la sanción. Claro está, que hay otros factores que determinan si alguien entra a la corrupción. Por ejemplo, si aumenta la disponibilidad de obtener ingresos legales, debido a la mayor calidad de la educación, se reducirían los incentivos a entrar en actividades ilegales y por lo tanto se reduciría el número de ofensas criminales. Es decir, el costo de oportunidad es también un factor importante, al ser este costo menor son mayores los incentivos para entrar a la corrupción.

Parece ser que de lo anterior se podría decir que la solución más simple y económica sería simplemente aumentar la sanción. Sin embargo esto no es siempre cierto, pues pueden ocurrir dos cosas. La primera es que el sobornado (en el caso del soborno) pida un mayor soborno, para compensar por el aumento en costos, debido a la mayor sanción. Este monto extra podría ser usado para corromper a las autoridades responsables de supervisar la corrupción y así disminuir la probabilidad de ser sancionado. Lo segundo que puede pasar es que la sanción, al ser tan alta, puede inducir a que la autoridad que aplique un menor número de sanciones. Esto llevaría consecuentemente a una menor probabilidad 
de ser sancionado al actor corrupto. Lo que entonces sería más eficaz para disuadir la corrupción sería aumentar la probabilidad de sancionar a los actores corruptos. Sin embargo, aumentar la probabilidad de que se sancioné a los actores corruptos es costoso; hay que considerar los daños que causa la corrupción y los costos de reducirla para determinar la cantidad óptima de crímenes, y así implementar las políticas eficientes. Existen más factores que determinan el nivel de actos corruptos. Como ya se mencionó anteriormente, el costo de oportunidad es un factor importante, pero también otro factor importante sería los costos relacionados con la actividad corrupta. Por ejemplo, si un burócrata puede falsificar un trámite a un menor costo que los demás, tiene una ventaja que le crea incentivos a entrar (o permanecer) en la corrupción. ${ }^{14}$

\subsection{Carta tabasco y la lucha con la corrupción}

Los pasados 30 de septiembre y 1 de octubre de 2013, se llevó a cabo en la ciudad de Villahermosa, Tabasco, el "Foro internacional para prevenir la corrupción", evento organizado por diversas instituciones, entre las que sobresalen el gobierno del estado de Tabasco y el Instituto Nacional de Administración Pública, y que congregó a funcionarios públicos, especialistas y académicos de una veintena de países. ${ }^{15}$

La Carta Tabasco, interesante documento emanado de las conclusiones del Foro, propone medidas para garantizar gobiernos honestos, eficientes y eficaces, entre las que destacamos las siguientes:

- Reformar el Poder Judicial para especializar una parte del mismo en derrotar a la impunidad.

- Construir un marco legislativo, normativo y organizacional que contribuya a mejorar la capacidad de respuesta de las instituciones públicas, orientada por elementos que hagan efectiva la prevención de

14 Buscaglia, Edgardo. (1999), "Judicial Corruption in Developing Countries: Its Causes and Economic Consequences", Essays in Public Policy, Hoover Institution.

15 Francisco Espioza. (2013). La carta Tabasco y la lucha contra la corrupcion. 18 de Diciembre de 2013, de SDPNoticias Sitio web: http://www.sdpnoticias.com/columnas/2013/12/18/la-carta-tabasco-y-la-lucha-contrala-corrupcion 
la corrupción, mediante la profesionalización de los servidores públicos.

- Convertir las aspiraciones anticorrupción en una política de Estado que involucre a todos los sectores de la vida pública

Una política de estado en materia de combate a la corrupción es la que se pretendía implementar con la creación de la Comisión Nacional Anticorrupción, propuesta por el presidente de la república. Lamentablemente, la propuesta se ha estancado, en lo que más que displicencia legislativa, se percibe como un abandono de la idea de luchar verdaderamente contra la corrupción, lo cual no deja de ser un contrasentido en momento en que, mediante una reforma fiscal, se pretende dotar de mayores recursos a los 3 órdenes de gobierno. La pregunta es: ¿para qué más recursos teniendo en cuenta los actuales niveles de corrupción y el ineficiente ejercicio del gasto público? Espero los legisladores tengan la respuesta y si no, que le echen un vistazo a la Carta Tabasco.

\section{Conclusion}

Los índices de confiabilidad demuestran que la mayoría de los funcionarios judiciales son aptos para estar en el desempeño de sus labores, ya que los exámenes que se les presentan de confiabilidad tienen muy buenos resultados, por lo visto solo queda en los exámenes, los ciudadanos tabasqueños dicen lo contrario. En la práctica y en el desempeño de sus labores estos funcionarios muestran poca confiabilidad, puesto que los procesos, las detenciones los malos manejos de contratos y las distintas irregularidades que presenta esta dependencia todo esto permea un foco para que se desarrolle la corrupción, pero más que ello va hacia la cultura que tiene muy arraigada el mexicano.

Tampoco podemos seguir culpando al gobierno de las irregularidades por que nosotros somos quienes deberíamos de exigir al poder político mejores instituciones con mayor eficiencia, los ciudadanos no exigen porque no conocen de sus derechos. 


\section{Bibliografía}

Ades, Alberto y Di Tella, Rafael. (1997), "National History Champions and Corruption: Some

Unpleasant Interventionist Arithmetic", Economic Journal, vol. 107, pp. 1023-1042.

Codigo Penal Federal

Maria Amparo Casar. (2010). Anatomia de la corrupcion. Mexico, DF.: CIDE.

Ley anticorrupción en contrataciones publicas

Daniel Márquez Gomez. (2015). El nuevo sistema de combate a la corrupción en México. 27 de mayo de 2015, de Universidad Nacional Autónoma de México Sitio web: http://biblio.juridicas.unam.mx/ revista/HechosyDerechos/cont/27/art8.htm

Morris, Stephen. (1991), Corruption and Politics in Contemporary Mexico, Tuscaloosa, University of Alabama Press.

Loret de Mola, Carlos. (2000), Impacto económico del narcotráfico en México: Estimación de las utilidades de los cárteles y su influencia sobre el nivel de vida de las familias productoras de droga en Badiraguato, Sinaloa, Tesis de Licenciatura, ITAM.

Buscaglia, Edgardo. (1999), "Judicial Corruption in Developing Countries: Its Causes and Economic Consequences", Essays in Public Policy, Hoover Institution.

Francisco Espioza. (2013). La carta Tabasco y la lucha contra la corrupcion. 18 de Diciembre de 2013, de SDPNoticias Sitio web: http://www.sdpnoticias.com/columnas/2013/12/18/la-carta-tabascoy-la-lucha-contra-la-corrupcion 
